\title{
Transformação dos principais usos da floresta no município de Moju, nordeste paraense
}

Liliane Freitas Moreira - Engenheira Agrônoma, Professora de Ciências Agrárias do IFPA, Campus Conceição do Araguaia, Pará e Mestre em Agriculturas Familiares e Desenvolvimento Sustentável pela UFPA. E-mail: liaacapu@yahoo.com.br.

Dalva Maria da Mota - Doutora em Sociologia, Pesquisadora da Embrapa Amazônia Oriental e Professora do Programa de pós-graduação em Agriculturas Familiares e Desenvolvimento Sustentável da UFPA. Bolsista de Produtividade do CNPq. E-mail: dalva@cpatu.embrapa.br

Acácio Tarciso Moreira de Melo - Engenheiro Agrônomo, Mestre em Agriculturas Familiares e Desenvolvimento Sustentável pela UFPA. E-mail: atmmelo@yahoo.com.br.

\section{Resumo}

As reflexões aqui apresentadas foram resultantes de uma pesquisa realizada na comunidade Santa Maria, uma das comunidades componentes do Assentamento Olho D’Água II, município de Moju, estado do Pará. O objetivo do artigo é analisar as transformações vivenciadas por um grupo de agricultores quanto ao uso da floresta, mais especificamente as associadas à obtenção de caças e à realização das roças, após a mudança da condição de uso comum (posseiros) para o uso privado (assentados) a partir da implantação do assentamento em 2002. Os resultados apontam que ocorreram transformações nas dinâmicas de uso dos recursos com a intensificação do cultivo de roças e a diminuição da obtenção de caças devido à grande dificuldade em obtê-las, em decorrência das novas condições de acesso privado à terra e ao aumento demográfico cuja demanda por caça supera em muito a oferta dos animais.

\section{Palavras-chave}

Florestas. Regime de propriedade. Assentamento. Caça. Roça.

\begin{abstract}
The ideas presented here resulted from a survey in the community of Santa Maria, part of Olho D'Água settlement, in the municipality of Moju, State of Pará, Brazil. The objective of the article is to analyze the transformations lived deeply for a group of agriculturists how much to the use of the forest, more specifically the associates to the attainment of huntings and the accomplishment of country, after the change of the condition of use joint for the private use from the implantation of the nesting in 2002. The study revealed significant reduction in capture of hunt by local farmers given to restricted access to hunting areas which are now privet and also given to higher demand caused by the increasing number of settled families.
\end{abstract}

\section{Keywords}

Forests. Property regimes. Settlements. Hunt. Slash-and-burn agriculture. 


\section{INTRODUCAO}

Partindo de exemplos concretos em que o uso comum de determinado recurso tem alcançado sucesso, Feeny et al. (2001) e Ostrom (1990) argumentam que as explicações de Hardin (1968) sobre a "tragédia dos comuns" são muito deterministas e diretas. Para aqueles autores, os regimes de propriedade comum podem ou não falhar, e Mckean e Ostrom (2001) ressaltam que alguns desses tipos de regime possuem pontos bastante negativos. Entretanto, segundo esses mesmos autores, em trabalhos mais recentes publicados em 1994, Hardin retificou a sua visão, passando então a distinguir recursos comuns não manejados e recursos comuns manejados. No primeiro caso, os recursos comuns estariam sujeitos à tragédia, devido à ausência de proprietários. Já no segundo caso, os proprietários, a partir de "direitos de propriedade" podem, segundo analisa o autor, "prevenir usos inadequados". Frente a isto, a tragédia dos comuns passou a ser associada ao problema da ausência de direitos de propriedade ou de regimes de manejo e não mais ao "compartilhamento do uso dos recursos", isto é, o uso comum.

Para Mckean e Ostrom (2001, p. 83), uma das vantagens da gestão comunitária ou coletiva é a “maneira de parcelar o fluxo de 'rendas' da colheita (o lucro) de um sistema integrado de recursos sem que haja parcelamento do capital em si”. O que seria, segundo esses autores, bastante vantajoso em "situações onde o manejo de um sistema de recursos é mais produtivo, quando este fisicamente se caracteriza como uma unidade coesa, ao invés de ser constituído por partes descoordenadas" (MCKEAN; OSTROM, 2001, p. 83), o que certamente contribuiria para que sistemas de recursos naturais fundamentalmente interativos (como, por exemplo, florestas controlam fluxos hidrográficos, espécies são interdependentes) fossem mais produtivos enquanto unidades maiores, isto é, maior rendimento produtivo quando comparado ao de parcelas individuais (MCKEAN; OSTROM, 2001).

Além dos "arranjos institucionais", outros dois fatores são fundamentais aos resultados do manejo de determinado recurso natural: a natureza do recurso e o regime de propriedade a que esse recurso esteja submetido. (FEENY et al., 2001, p. 20). Assim, poder-se-ia definir os recursos comuns, segundo o autor, como sendo uma classe de recursos para a qual a exclusão é difícil e o uso conjunto envolve subtração. Com relação aos regimes de propriedade, o autor apresenta quatro regimes de direitos de propriedade no âmbito dos quais os recursos de propriedade comum podem ser manejados, mas que devem ser apreendidos, segundo ele, como tipos analíticos ideais, como: o livre acesso, a propriedade comunal, a propriedade privada e a propriedade estatal, de forma que esses tipos complementam-se entre si, podendo também haver sobreposição e combinações conflitantes de categorias, além de variações em cada um deles (FEENY et al., 2001).

Nas análises de Feeny et al. (2001), os regimes de acesso livre são aqueles em que não há direitos de propriedade bem definidos; o acesso ao recurso não é regulado e é aberto a todos. Diferentemente, nos regimes de propriedade comum o recurso é apropriado por uma comunidade de usuários bem definidos; e são estes usuários quem regulam o uso e acesso aos mesmos. No caso da propriedade privada, os direitos de acesso e uso do recurso pertencem a um proprietário individual ou a uma corporação, que podem repassar seus direitos a outrem. E, no caso da propriedade estatal, o recurso é controlado por um governo central (quer no âmbito nacional, regional ou local), sendo o Estado o regulador do acesso e uso.

O extrativismo, que para Benjamim (2003, p. 31) é "a coleta dos produtos da floresta", vem sendo realizado desde os primórdios da humanidade e tem garantido, ao longo dos tempos, a sobrevivência das populações que residem em áreas de florestas. É o caso das famílias que vivem nas florestas da região amazônica, para quem as atividades extrativistas têm sido, há muito tempo, atividade principal e/ ou complementar (ALLEGRETTI, 1996; BENJAMIN, 2003; SIMONIAN, 2000), razão pela qual estes autores se opõem às análises de Homma (1993) a respeito de que o extrativismo "está fadado a desaparecer", e ressaltam que as análises sobre isso não podem ser realizadas exclusivamente em termos econômicos, já que elas também desempenham uma função social e ambiental.

Essa função fica evidente quando se analisa com as transformações no acesso e uso dos recursos têm implicado, também, nas formas como os seus praticantes se vêem. É interessante observar que no passado os entrevistados se autodenominavam lavradores e, alguns destes, também como extrativistas. A primeira autodenominação foi mudada mais recentemente para agricultores familiares por influência de diferentes atores externos (como por exemplo, INCRA e STR de Moju), quando do processo de implantação do Assentamento Olho D'água II.

É exatamente por este motivo que considerei a agricultura familiar como uma categoria central nas minhas reflexões, entendendo que se refere a uma forma de organização produtiva, cujos critérios que orientam as decisões com relação à exploração agrícola não consideram apenas a produção/rentabilidade 
econômica, mas também os objetivos da família e suas necessidades; o que se contrapõe ao sistema patronal, visto que neste há total separação entre gestão e trabalho (WANDERLEY et al., 1993).

Em se tratando dos assentamentos, Carmo (2005, p. 229) afirma que os assentamentos "constituem a forma sui generis que o Estado brasileiro encontrou para realizar a reforma agrária, em resposta às pressões dos movimentos sociais na militância pela posse da terra". Constituem-se, na grande maioria, a partir de conflito ${ }^{1}$ social, ao que Neves $(1999$, p. 2) atribuiu serem os assentamentos, respostas pontuais às pressões dos trabalhadores pela "posição social de titular de lote de terra". E é a partir de então que o direito da posse definitiva de uma terra lhe é assegurado (LEITE et al., 2004), devendo cumprir a sua função social, em concordância ao Estatuto da Terra de 1964.

Segundo Martins (2003), o acesso à terra, por meio do assentamento promove mudança de mentalidade do "assentado". Para esse autor, os assentados, proprietários de terras e protagonistas de um direito, são sujeitos submetidos às tensões inerentes à expressão "proprietário de terra", e adverte para que qualquer análise a respeito disso não seja generalizada, mas fundamentada a partir do conhecimento da vivência, isto é, diante das práticas cotidianas e do modo como o assentado experimenta as alterações da situação social promovida pelo assentamento. Razão pela qual, entre outras, a instituição de assentamentos recebe o atributo de "processos sociais complexos" (NEVES, 2005, p. 80).

O objetivo deste artigo é exatamente tratar de um destes processos, qual seja, aquele que implicou nas transformações quanto aos usos da floresta na comunidade Santa Maria, assentamento Olho D’Água II, município de Moju, nordeste paraense, influenciando nas categorias de autodenominação, quais sejam: lavrador e extrativista no passado (antes do assentamento) para agricultor familiar no presente.

O olhar especial ao assentamento Olho D’Água II ateve-se ao fato de sua formação social ser de uma população local ${ }^{2}$, que desde o início do século XX já habitava na área onde hoje se configura este assentamento, diferentemente da maioria dos assentamentos do Brasil, os quais apresentam uma grande diversidade

Segundo Glasl (1997, apud SCHMITZ; MOTA; SILVA JUNIOR, 2006), o conflito social é definido como "uma interação entre atores na qual pelo menos um ator vivencia incompatibilidade no pensamento, na representação, na percepção, no sentimento ou no querer com um outro, assim que na ação ocorre um impedimento através do outro".

2 Neste trabalho, considera-se a expressão população local ou residente, a partir do exposto por Barreto Filho (2006), para o qual, essa expressão é a mais conveniente para referir-se á população original, população nativa, tratada por alguns autores, entre os quais Diegues (2002), pelo termo de "tradicionais". social de origens, de experiências, de trajetórias e aspirações dos assentados (MARTINS, 2003; MEDEIROS; LEITE, 1999). Essa escolha se deu, ainda, e principalmente, em razão das mudanças que ocorreram no uso da floresta pelas famílias que ali residiam após a constituição do mesmo, quando o acesso às áreas de floresta que antes era comum tornou-se privado ${ }^{3}$, em lotes individuais.

Dentre as três comunidades ${ }^{4}$ existentes no referido assentamento, a opção de realizar a pesquisa com as famílias da comunidade Santa Maria se deu em virtude de ser esta a que apresenta o maior número de famílias nativas ${ }^{5}$ : trinta e duas (32), de um total de quarenta e duas (42) famílias alocadas nessa comunidade. Optouse, também, por realizar a pesquisa junto a todas as famílias nativas presentes na comunidade durante a realização do trabalho de campo, obtendo-se assim uma amostra de 28 famílias, sendo que em quatro, um dos filhos de maior idade também detém um lote e, nestes casos, considerado como extensão do lote das suas respectivas famílias.

No geral, na maior parte dos casos, os homens detinham o papel central das entrevistas, sobretudo por serem considerados os principais representantes de suas famílias, os quais em sua maioria possuíam entre trinta (30) a cinquenta (50) anos de idade.

A semelhança do que foi observado por Mota et al. (2007) em outro contexto na região do alto Moju (nordeste paraense), a população residente tem abandonado algumas práticas extrativistas, em decorrência da escassez de floresta. Neste caso, a população tem constituído novas estratégias de sobrevivência, investindo mais na agricultura, o que, segundo eles, coloca em risco a sobrevivência e reprodução social das suas famílias, devido à forte dependência que elas têm dos recursos da floresta.

Na comunidade Santa Maria, essas estratégias têm se baseado na roça, que se configurava, ao mesmo tempo, um espaço social, onde praticamente todos os membros da família participavam, e um espaço de cultivo agrícola, onde era possível

3 A partir da constituição do assentamento, em 2002, as famílias residentes adquiriram a Autorização de Ocupação e Uso da Terra, ocasião em que cada família obteve um lote, que em média é de 50ha, desde então autodenominam-se proprietários. Segundo o regime do assentado, após a demarcação dos lotes os assentados detêm o título de domínio, o que lhes garante a propriedade da terra, entretanto, não podem vendê-lo ou repassá-lo a terceiros.

4 Além da comunidade Santa Maria, existem nesse assentamento outras duas comunidades: Limoeiro e Monte das Oliveiras, todas já constituídas quando da implantação do mesmo, mas reconfiguradas após isso.

5 Assim denominadas por serem famílias que já habitavam a área desde muito antes da implantação do assentamento. 
obter parte dos bens necessários à sobrevivência. Essa participação diferenciavase segundo o sexo e a idade dos membros e, dependendo disso, destinava-se as tarefas a serem executadas, bem como o tempo empregado por cada um.

\section{OS USOS DA FLORESTA: AS ROÇAS E AS CAÇAS}

O uso da floresta representa o principal meio de vida dos agricultores familiares que vivem na atual comunidade Santa Maria, espacializada no assentamento Olho D’Água II, região do nordeste paraense, município de Moju. A implantação deste assentamento ocorreu em 2002 e modificou a condição de acesso às áreas de floresta, antes comum, na condição de posseiros, para o uso privado após assentamento. Além disso, tem ocorrido um expressivo aumento demográfico.

$\mathrm{Na}$ região do nordeste paraense, a gênese dos assentamentos rurais tem forte relação com o processo de ocupação e formação fundiária que se deu ali (SOUSA, 2002). Loureiro e Pinto (2005) enfatizam que nesta região incidiram vários conflitos sociais entre grileiros e populações que há décadas já habitavam nas terras griladas, a exemplo do ocorrido com a população que constituiu o assentamento estudado.

A implantação do assentamento, que ocorreu em 2002, estabeleceu o regime de propriedade privada e modificou a forma de acesso às áreas de floresta, promovendo, com isso, transformações nos usos deste recurso, principalmente com relação à obtenção de caças e à realização de roças, cujos produtos constituíam os principais itens da dieta alimentar das famílias da comunidade Santa Maria. No presente, a obtenção da caças tornou-se menos frequente, e essas mudanças incidiram nos hábitos alimentares dos entrevistados e em seu contexto social, os quais são bastante significativos para eles. Assim, o principal uso da floresta é para a realização de roças, de onde provém parte dos alimentos necessários à sobrevivência. De um lado, os entrevistados ressaltaram que precisam dedicar bastante tempo e esforço para esse tipo de trabalho e, dessa forma, dispõem de menos tempo para outras atividades como as caçadas. De outro, o acesso às áreas de floresta na comunidade Santa Maria é privado, sendo o uso deste recurso exclusivo ao proprietário do lote. Para o caso da caça, a atual configuração socioespacial inviabilizou as regras que foram instituídas e mantidas pelas famílias durante décadas.
Segundo os entrevistados, até 2002 existiam os seguintes tipos de regime de propriedade: áreas próprias (com ou sem a posse jurídica); áreas devolutas (ausência de direitos de propriedade bem definidos); áreas arrendadas e áreas concedidas (comodato). Isto possibilitava os diversos usos da floresta, dentre eles a caça e a roça, os quais eram os de maior importância para a alimentação das famílias que residiam na área da comunidade Santa Maria, sendo que as roças geralmente eram realizadas em pequenas dimensões, apropriando-se, para isso, de áreas relativamente pequenas, traduzindo-se nas falas dos entrevistados como "pedacinhos de roça".

Para isso, foram estabelecidos alguns acordos, os quais fazem parte do que Ostrom (1990, p.91) define por "instituições", termo que, segundo a autora, pode ser entendido como: "um conjunto de regras de trabalho que determinam, entre outros, os participantes, as ações permitidas ou proibidas, as informações necessárias e a distribuição de benefícios".

Segundo as informações levantadas, as "caças" eram consideradas "divinas", pois eram providas por Deus, e por isso pertenciam a todas as pessoas, para as quais o acesso às áreas de floresta era permitido, principalmente, porque a disponibilidade desse recurso era farta.

Apesar das afirmações de Hardin (1968) quanto à inexistência de direitos de propriedade bem definidos, com relação ao acesso aos recursos comuns, isso não corresponde ao caso das famílias da comunidade estudada. Durante décadas constituíram regras e acordos, tais como: todas as pessoas residentes na comunidade podiam usar a floresta; um segundo caçador somente permaneceria numa determinada área se o que lá já estivesse desse a permissão para isso; a quantidade de caças deveria ser apenas a necessária ao consumo doméstico.

Então, dos diversos usos da floresta (frutas, madeiras, caças, plantas medicinais e roças) dependia o próprio modo de vida das famílias da comunidade Santa Maria, sendo as caças terrestres e as roças os de maior importância tanto em termos sociais quanto econômicos, uma vez que eram esses usos que asseguravam a alimentação dessas famílias, como mostra o Quadro 1. 
Quadro 1. Atividades de maior importância para a aquisição dos principais alimentos.

\begin{tabular}{|l|l|c|c|}
\hline \multicolumn{1}{|c|}{ Ordem } & \multicolumn{1}{|c|}{ Atividades } & Número de famílias & $\%$ \\
\hline 1 & Roças & 28 & 100 \\
\hline 2 & Caças & 27 & 96 \\
\hline 3 & Pesca & 18 & 64 \\
\hline 3 & Extração madeireira & 18 & 64 \\
\hline 4 & Criação (suínos e aves) & 11 & 39 \\
\hline 5 & Extração do açaí & 4 & 14 \\
\hline
\end{tabular}

De acordo com o Quadro 1, podemos perceber o quanto a roça e a caça representaram à base alimentar do grupo social alocado naquela comunidade, já que quase $100 \%$ dos entrevistados afirmaram que essas duas práticas eram realizadas em suas famílias. Tais práticas eram efetuadas, como relataram os entrevistados, a partir do acúmulo dos vários conhecimentos que detinham sobre os recursos naturais, o que Diegues (1996) caracteriza como sendo o conhecimento construído a partir das relações entre homem e natureza e que pode ser denominado de "conhecimento tradicional", ou seja, o saber e o saber fazer sobre o mundo natural.

\section{Roça: negócio da família ontem e hoje}

Durante toda a pesquisa de campo observou-se o empenho das pessoas nas atividades da roça ou relacionadas a ela, principalmente na fabricação de farinha. Neste caso, todos os membros da família que pudessem participar eram envolvidos. Por ser o período de férias escolares, as crianças podiam se dedicar mais, tanto nessa quanto nas demais atividades e, segundo seus pais, a contribuição delas, mesmo quando ocasional, é uma importante ajuda.

O relato abaixo é de um entrevistado que descreve a respeito das roças:

"A gente faz o roço, derruba e depois toca fogo e planta tudinho, aí depois tem as capinas. Com um ano a gente tira tudinho e fica só a capoeira, aí ela vai crescer. No outro ano a gente tem que fazer outra roça, aí vai fazer lá para o outro lado até essa capoeira crescer para ficar no ponto para tornar a fazer roça nela! Para isso ela tem que crescer pelo menos uns 5 anos, mas às vezes não tem jeito não, a gente só deixa é 3 anos, porque não tem outro jeito" (L.G., 38 anos, lavrador e extrativista).
Para a realização das roças os entrevistados utilizavam a técnica conhecida como corte e queima. Essa técnica constitui-se uma tradição milenar (ADAMS, 2000; LEAL, 2002; OLIVEIRA, 2002) e consiste nas seguintes etapas: roço, derruba, e queima da floresta (nativa ou capoeira ${ }^{6}$ ), seguida do plantio dos cultivos das culturas alimentares (principalmente mandioca, arroz e milho), capina (remoção de plantas invasoras ou plantas daninhas, técnica que foi alterada depois da evidência da agroecologia e da possibilidade dessas plantas poderem servir de apoio ao cultivo principal), colheita e pousio (repouso dado às terras cultiváveis por certo período de tempo).

Há tempos questiona-se a viabilidade desse modelo de agricultura associada ao predatório, arcaico e irracional. Entretanto, raras são as análises que discutem o tema de forma crítica sem se limitar a "verdades já provadas", quando, no entanto, deveriam ser embasadas e analisadas a partir de pesquisas a esse respeito (HURTIENE, 2005).

Autores como Hurtiene (2005), Felipim, Resende e Ribeiro (2000), Adams (2000) e Leal (2002) comungam da ideia de que a viabilidade ecológica e econômica desse tipo de agricultura está diretamente relacionada a algumas condições, dentre as quais a baixa densidade demográfica e o período de pousio, que asseguram o restabelecimento da fertilidade do solo cultivado.

Para o caso em análise, a baixa densidade demográfica perdurou até o início da década de 90, quando residiam na comunidade apenas vinte e oito famílias. Naquele período, a demanda por floresta para o cultivo das roças ainda era relativamente pequena, principalmente quando comparada à quantidade de floresta disponível e em condições de uso, fato que contribuía para a viabilidade do sistema de corte e queima realizado por aquelas famílias. O corte e queima ainda é a técnica utilizada para a realização das roças, isto é, transforma-se a floresta em fonte nutricional para os cultivos.

Apesar das famílias poderem fazer roças em outras partes da floresta, tinham preferência em utilizar as suas próprias áreas, pois o deslocamento e o transporte de produtos era muito penoso e demorado e, também, porque favorecia as mulheres e crianças a participarem das atividades. Além do mais, contribuía para a maior

\footnotetext{
Capoeira é uma das denominações populares para a vegetação secundária. Para a agricultura itinerante, as áreas de capoeira representam uma etapa de recuperação da fertilidade do solo, a fim de que após um período de pousio (recuperação) as mesmas possam ser novamente utilizadas. Nos trabalhos de Homma et al. (1998), essa vegetação apresenta a seguinte classificação: capoeirão, vegetação secundária com mais de 10 anos depois da última derrubada; capoeira, vegetação secundária entre 4-10 anos; e, juquira, vegetação secundária com até dois anos.
} 
sociabilidade entre os vizinhos, uma vez que residindo próximo aos cultivos, as redes de ajuda poderiam ser mais frequentemente utilizadas.

Mas, essa configuração vem se modificando, pois segundo os entrevistados houve um aumento significativo da quantidade de área (ha) de floresta utilizada para a realização de roças (Quadro 2). Isso porque "de uns anos para cá a gente está passando a viver mais da roça” (M.D.P., 59 anos, lavrador e extrativista) e, por isso, os "pedacinhos de roça" do passado não são mais suficientes para garantir o consumo de suas famílias. No presente, a média da quantidade de área (ha) de floresta utilizada é de 2,3ha, isto representa um aumento de aproximadamente $35 \%$, quando comparado ao passado que era de 1,7 ha.

Quadro 2. Quantidade de área (ha) de floresta usada para a realização das roças.

\begin{tabular}{|c|c|c|c|c|c|c|c|}
\hline \multirow{2}{*}{ Período } & \multirow{2}{*}{ Total de } & \multicolumn{6}{|c|}{ Área de floresta usada para a realização da roça (ha) } \\
\cline { 3 - 8 } & Famílias & $\begin{array}{c}0,5 \mathrm{a} \\
1,0\end{array}$ & $\begin{array}{c}1,1 \mathrm{a} \\
1,5\end{array}$ & $\begin{array}{c}1,6 \\
2,5\end{array}$ & $\begin{array}{c}2,6 \\
3,0\end{array}$ & $\begin{array}{c}3,1 \mathrm{a} \\
3,5\end{array}$ & $\begin{array}{c}3,6 \\
4,5\end{array}$ \\
\hline \multirow{2}{*}{ Passado } & $\mathbf{2 8}$ & 11 & 10 & 1 & 2 & 4 & 0 \\
\cline { 3 - 9 } & & $39 \%$ & $36 \%$ & $3 \%$ & $7 \%$ & $14 \%$ & $0 \%$ \\
\hline \multirow{2}{*}{ Presente } & \multirow{2}{*}{$\mathbf{2 6}$} & 5 & 8 & 7 & 0 & 2 & 4 \\
\cline { 3 - 9 } & & $19 \%$ & $31 \%$ & $27 \%$ & $0 \%$ & $8 \%$ & $15 \%$ \\
\hline
\end{tabular}

Devido à menor disponibilidade de floresta, frente à crescente necessidade de seu uso para a realização de roças, os intervalos de tempo do pousio têm sido menores. Alguns estudos como Leal (2002), Oliveira et al. (1994) e Hurtiene (2005) apontam que quando isso ocorre há uma considerável redução da eficiência da vegetação secundária em restaurar os nutrientes do solo necessário para a realização de uma nova roça. Isto possivelmente compromete a viabilidade do sistema de produção desses entrevistados (HURTIENE, 2005).

Ao tratar sobre isso, Oliveira et al. (1994, p.45) destacam que quando a prática de corte e queima é utilizada

"por populações numerosas, circunscritas em pequenos lotes rurais, o pousio é compelido a períodos menores, insuficientes para a restauração da fertilidade do solo. Sucessivamente com roças e pousios mais curtos, a área tende a se degradar e, a partir de então, mesmo com o seu abandono por períodos maiores, a sucessão não deve reconduzir a um estado de vegetação original - vê-se o fim da produtividade e a diminuição drástica da resiliência da área."
A problemática apresentada por esses autores é bastante pertinente para análise do caso aqui estudado, principalmente porque além dos entrevistados estarem "circunscritos em pequenos lotes" e disporem cada vez menos de área de floresta apropriada ao uso da roça, o tamanho da área utilizada é maior do que no passado.

Com relação à preparação das roças, há três tipos de acesso: privado (familiar), comum e comodato. Neste último caso, o acesso é permitido apenas a parentes ou compadres que não possuem lote ou quando estes dispõem de quantidade insuficiente de terra firme para a realização de roças para o autoconsumo familiar. Aliás, apenas com esta finalidade a permissão é dada, pois se partilha da compreensão de que cada família deve ter o necessário a sua sobrevivência diária, motivo pelo qual os produtos dali advindos não devem ser vendidos. O negócio seria incompatível com a lógica da doação da possibilidade de uso pelo proprietário, pois são transações cujos conteúdos são simbólicos, e não monetários.

$\mathrm{O}$ ato de ceder a floresta do lote para outras pessoas realizarem roça é pouco recorrente, em decorrência da menor quantidade de floresta disponível para esse tipo de uso e da preocupação dos pais com relação às áreas que destinarão aos seus filhos quando estes se casarem, como 'tradicionalmente' ocorria no passado. Também revela a preocupação que alguns entrevistados têm em relação à perda do domínio da terra no caso de vir cedê-la a outrem.

O acesso comum também é pouco recorrente porque as pessoas preferem fazer roça apenas no lote que lhe pertence. Apesar disso, três entrevistados relataram que o uso da floresta de seus lotes ainda permanecia sendo de uso comum, neste caso todos eles são parentes (um pai e dois filhos), podendo, neste caso, considerar um tipo de uso familiar. E, quanto às decisões com relação ao seu uso, sempre são discutidas entre eles.

O principal tipo de acesso à floresta para a realização de roças é o privado, e para isso os proprietários dependem fundamentalmente da disponibilidade desse recurso que há em seus lotes (salvo raras exceções), e ainda, restringido pela legislação ambiental vigente. No passado, embora a maioria das pessoas fizesse suas roças na área em que elas residiam, havia outras possibilidades de acesso como: livre acesso, acesso comum e o arrendamento. Além disso, suas áreas e a disponibilidade de floresta eram maiores.

Segundo os entrevistados as "recomendações" dos funcionários do INCRA acerca do uso da floresta para a realização de roças é de que não sejam maiores 
que 1 ha/ano. No entanto, isso não é suficiente para a produção necessária ao consumo da unidade familiar, principalmente diante da escassez de carne provida pela caça. Sendo assim, a quantidade de floresta destinada a esse tipo de uso tem sido cada vez maior. Por isso, embora a legislação ambiental vigente determine que a reserva legal dos lotes seja de $80 \%$ do total de sua área, os lotes dos entrevistados dificilmente conseguem atender essa exigência, o que já vem ocorrendo com a maioria (18) deles (Gráfico 1). Isso não tem sido mais relevante devido à quantidade de floresta de várzea, inviável ao plantio de roças.

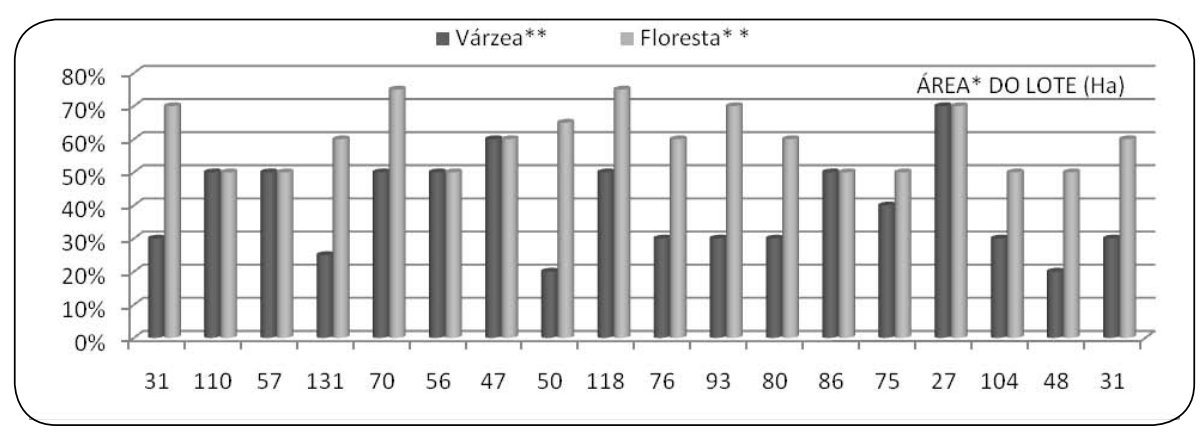

Gráfico 1. Área (ha) total, de floresta nativa ou capoeirão (\%), e de várzea (\%) do lote dos entrevistados que detêm menos de $80 \%$ de floresta nativa ou capoeirão.

* Obtidas através do cadastro do INCRA.

** Obtidas a partir das informações dos entrevistados.

No caso do acesso à floresta para a realização das roças, raramente ocorrem conflitos, tanto que somente duas situações foram relatadas. Em uma, dois proprietários se desentenderam com relação à divisa entre seus lotes. $\mathrm{Na}$ outra, um destes proprietários teve seu lote "invadido" pelo vizinho, o qual alegou a necessidade da floresta para a realização de suas roças, com a justificativa de que os donos pouco a usavam para este fim. No entanto, após as observações e conversas constatou-se que esse "invasor" ainda possui em seu lote uma boa quantidade de floresta disponível para o plantio dos cultivos da roça, revelando com isso, que seu principal interesse incide sobre a madeira que há naquele lote e sobre a sua possível obtenção.

Apesar da intervenção do presidente da associação não ter conseguido resolver o problema, contribuiu para que o mesmo não se agravasse. Posteriormente, essa situação foi questionada junto ao INCRA, que ainda não se manifestou oficialmente.
De maneira geral, os conflitos com relação às roças somente ocorrem por causa da entrada de suínos, visto que esses animais são criados soltos no lote e facilmente invadem as roças adjacentes, ocasionando prejuízos aos cultivos, em especial à mandioca.

Para evitar maiores desentendimentos com seus vizinhos, e mesmo porque muitas vezes as vítimas dos prejuízos com a produção da roça acabam sendo os próprios proprietários desses animais, as criações são desfeitas. Porém, ao se desfazerem de suas criações perdem uma importante fonte de alimentação, principalmente diante da diminuta obtenção das caças. No entanto, segundo os entrevistados, essa é a decisão mais sensata, tendo em vista que os suínos são animais de difícil controle de fuga, mesmo quando são criados em locais cercados, que denominam de "chiqueiros". Além disso, esse tipo de criação é mais oneroso, principalmente em termos de alimentação, e, deve-se considerar, também, que esta prática não se constituiu predominante, e, portanto, há menos conhecimento a respeito.

Para as atividades da roça, as famílias recorrem a diversas estratégias e dependem fundamentalmente da mão de obra familiar. As práticas de mutirão são utilizadas principalmente para as atividades de roço e derruba, mas são menos recorrentes do que no passado, em especial por causa do aumento do uso da motosserra, que contribui para aumentar a possibilidade de realização daquela tarefa com menos pessoas.

O mais recorrente é a troca de dia entre parentes e vizinhos próximos e é realizada principalmente para as atividades que demandam maior tempo e esforço. Prática que os “[...] trabalhadores por necessitarem de força de trabalho superior a disponível na unidade familiar e não dispondo de recursos financeiros que os possibilite pagar por esta força de trabalho, lançam mão da permuta entre outros que se encontram na mesma situação" (LACERDA; MALAGODI, 2007, p.97).

Os entrevistados que dispõem de pouca mão de obra familiar, quando possuem algum recurso financeiro contratam uma pessoa para trabalhar nas atividades que tiverem maior necessidade no momento, sendo o roço e a derruba as principais. Porém, é um caso que dificilmente ocorre. Os principais instrumentos para a realização das atividades da roça são: a motosserra e o machado (derruba); a foice e o terçado (roço, colheita do arroz e da mandioca); e a enxada (plantio e capinas). 


\section{Caça: solução divina do passado, problemas no presente}

Uma característica peculiar das pessoas da comunidade estudada é a valorização positiva e negativa do uso das caças, devido à idealização do passado se mesclar com a escassez do presente e, principalmente, por causa da crescente valorização das roças. Se no passado um caçador conferia status dentro da comunidade, no presente representa a sua inferioridade social, devido à impossibilidade dessa atividade prover a sobrevivência e reprodução familiar, $\mathrm{O}$ que no presente é assegurada através da venda dos produtos da roça.

Isso provavelmente contribuiu para mudar a concepção que os entrevistados têm quanto às diferentes atividades, sendo que a caçada não é mais considerada como trabalho, mas lazer. Outra influência deriva da influência dos técnicos do INCRA, que não concebem tal atividade como trabalho. Segundo os entrevistados, as suas recomendações é que eles “trabalhem”, referindo-se ao cultivo agrícola e/ ou a criações, como pode ser observado no trecho do relato de um entrevistado: "é porque ninguém se dedica a criar as caças, apenas as obtêm".

As caças mais utilizadas pelas famílias são o tatu (Priodontes maximus), o veado (Mazama americana e Mazama gonazoubira) e a paca (Agoutipaca). Além dessas, também são obtidas: guariba (Alonatta belzebul), mucura (Didelphis marsupialis) e cutia (Dasyprocta azarae). O consumo dessas espécies foi observado durante toda a pesquisa de campo. Embora no passado essas duas últimas raramente fossem utilizadas para o consumo familiar, atualmente fazem parte da sua alimentação, fato que possivelmente está associado à crescente escassez de animais, o que, conforme considera Huss-Ashmore e Johnston (1997, apud SILVA, 2007, p.156), “da escassez à extrema situação de fome, parece haver uma escala de mudanças em que alimentos geralmente evitados são consumidos".

Quanto aos métodos utilizados para a obtenção das caças, no presente, os principais são: a varrida e a espera, não diferindo de como eram realizadas no passado. No método de varrida, primeiramente o caçador escolhe um local, de preferência onde houver algum rastro de caça e, posteriormente, limpa-se (retirase folhas e galhos) um caminho pelo qual ele percorre para tentar a captura. No método da espera, o caçador aguarda o animal em pontos específicos: árvores em frutificação ou nas margens de cursos d'água (rios e igarapés), escolhido após a constatação de algum rastro (pisadas, cheiros, abrigo, ou outro) de caças e da construção de um jirau (um estrado de madeira utilizado para observar a caça) na própria árvore ou em área próximas; ou/e, ainda, apenas se dirige até as margens e escolhe um determinado local onde permanece à espera da caça.
Apesar de todos os entrevistados terem relatado que as caças não são mais a principal fonte de alimentação, cinco deles (18\%) afirmaram que esse recurso ainda contribui significativamente para a dieta alimentar de suas famílias, fato constatado durante toda a pesquisa de campo por meio das observações e/ou pelos relatos:

"Quando os meus filhos vão caçar e conseguem pegar alguma caça ajuda muito. Por exemplo, todos estes dias nós estamos comendo a caça que eles estão trazendo se a gente passar dois dias comendo uma caça que eles mataram a gente já não gasta o dinheiro que iria comprar a bóia para comer [...] (M.D.P., 59 anos, lavrador e extrativista).

A menor ou nenhuma frequência do consumo das caças para a dieta alimentar das famílias dos entrevistados deve-se à reduzida disponibilidade desse recurso. Constatação semelhante foi feita por Oliveira, Carvalho Junior e Chaves (2004) em algumas comunidades por eles estudadas. Neste estudo, isso passou a ocorrer após a implantação do assentamento, pois além da privatização das florestas, a qual no passado as pessoas tinham acesso para realizarem as suas caçadas, a quantidade de caças e também de floresta é menor, devido à maior demanda que houve por esses dois recursos.

A possibilidade do acesso e uso da floresta das comunidades próximas tem sido para algumas famílias (5) uma importante estratégia para a obtenção das caças. No entanto, essas possibilidades são cada vez menores devido à constante redução da floresta e/ou à venda das propriedades dessas comunidades a pessoas ou empresas que pró́bem o acesso, como foi o caso da empresa de Dendê BioPalma, que se instalou no entorno da comunidade no final de 2007. Outro modo de obtenção das caças é o uso da floresta de parentes (consanguíneos de grau mais próximo) que em alguns casos são utilizadas de forma comum, o que aumenta as possibilidades da realização e do êxito na caçada.

Apesar da maioria dos entrevistados ainda realizar caçadas, elas ocorrem com menor frequência do que no passado. Além disso, o número de entrevistados que abandonaram essa atividade é significativo (26\% do total da amostra).

Uma das explicações para esta diminuição está no fato das pessoas terem que dedicar um grande intervalo de tempo para a obtenção de alguma caça, mas, principalmente, porque não há nenhuma garantia que obterão algum animal, o que significa para os entrevistados "perder tempo". Os entrevistados explicitam que o tempo deve ser empreendido em outras atividades que assegurem o necessário para a alimentação dos membros da família. Além disso, apesar dos técnicos do INCRA atuarem bem pouco nessa comunidade, suas "recomendações" acerca da 
obtenção das caças constituíram a base das novas regras que foram estabelecidas, as quais são: evitar as obtenções de caças; proibir as obtenções de caças fêmeas, a quaisquer condições; vetar as caçadas com cachorro e caçar apenas no lote que lhe pertença.

Nos casos em que se permitem que parentes consanguíneos de grau mais próximo tenham acesso às florestas para que realizem as caçadas, estes devem sempre "pedir permissão ao dono do lote antes de entrar na floresta, e com o qual se divide a carne que for obtida durante a caçada" (M.P.R., 49 anos, lavradora e extrativista), pois isso ratifica seu "direito" enquanto proprietário, além de ser essa uma forma de controlar a entrada de outras pessoas em seu lote.

No passado, raramente alguém desrespeitava as regras. No presente, entretanto, as transgressões tornaram-se práticas comuns, principalmente no que se refere às "invasões" aos lotes. A maioria das queixas dos entrevistados é com relação a este fato, pois, segundo eles, as pessoas nem ao menos lhes pedem licença, no entanto, reconhecem que dificilmente alguém permitiria isso (exceto nos casos citados), conforme se pode constatar no seguinte relato:

[...] "Hoje em dia você tem que proibir porque cada um já está no seu lugar e não tem espaço para mais nada. Você não pode nem permitir porque sendo proibido eles já entram e pegam, e se a gente deixar o outro vir caçar vai acabar com o pouco que tem. Então a gente não deixa os outros virem matar, quando escuto cachorro no mato eu vou lá e mando quem está caçando ir embora, porque nem eu caço com cachorro, não faço varrida preservando o que ainda tem. Antigamente o pessoal tinha mais consideração e respeito” (L.G., 38 anos, lavrador e extrativista).

Acerca dessas “invasões", todos os entrevistados relataram que os conflitos são cada vez mais recorrentes, principalmente quando comparados ao passado. Os conflitos mais graves são aqueles em que a caçada é realizada com cachorro, porque além da ocorrência da "invasão" ao lote, o cachorro é animal que espanta e desvia as caças para locais distantes de onde elas estavam, o que prejudica ainda mais sua obtenção pelos proprietários do lotes "invadidos", pois leva à escassez de caças nas proximidades, fato que não ocorria no passado, o que fica evidente no relato abaixo:

"Não era mais para ninguém caçar com cachorro para não espantar a caça, porque cachorro espanta muito a caça! Ela vai embora para longe, espanta e muito! Antes não tinha este problema porque a caça era mais! Mas o pessoal do lado do rio não respeita isso e caça com cachorro, aí a caça foge para longe. Quer dizer que ele tira de dentro do meu terreno e leva para outros. É por isso que a gente acha ruim, a senhora não acha?” (M.R.R., 69 anos, aposentado)
Nas comunidades estudadas por Almeida et al. (2002), também ocorrem conflitos entre vizinhos por causa das caçadas com cachorros, pois embora os latidos destes animais auxiliem o caçador a identificar o rumo quando alertam sobre a caça, seu latido a espanta para longe, valendo-se então da expressão dita pelos moradores: "cachorro, quando não mata, espanta". Conforme descrevem os autores, os Kaxinawa e os seringueiros do Alto Juruá relataram que "o resultado visível da introdução e a disseminação de cachorros" é a escassez da caça. E, conforme é avaliado localmente, o caçador que caça com cachorro priva seu vizinho da possibilidade de caçar. Por esses motivos, decidiu-se em Assembleia da Associação dos Seringueiros e Agricultores da Reserva Extrativista do Alto Juruá que a caçada com cachorros ficaria proibida no Plano de Utilização da mesma.

No caso da comunidade aqui estudada, apesar de alguns proprietários não oficializarem as reclamações a respeito das "invasões" em seus lotes, os registros sobre isso realizados junto ao presidente da associação já totalizam 23 , embora alguns sejam apenas reincidências. Além de efetuar os registros das reclamações, $O$ presidente também é o responsável por intermediar os conflitos, e até então tem conseguido resolvê-los, conforme descrito no relato abaixo:

"Quando essas confusões ocorrem, eles vêm aqui comigo e me relatam o que aconteceu, e eu asseguro que resolverei o caso. Vou dormir pensando como poderia resolver. No outro dia acordo bem cedo, às vezes ainda é de madrugada e vou lá conversar com a outra pessoa envolvida. Converso bastante antes de entrar no mérito da questão, até que eu faço a pergunta para a pessoa e já conversamos sobre o problema, aí pronto! Decidimos tudo entre nós dois na conversa. Geralmente é assim que acontece, porque se um for pessoalmente conversar com o outro, é capaz de dar briga!" (J.R.S., 49 anos, lavrador e extrativista).

As questões a respeito das "invasões" aos lotes e sobre as novas regras estabelecidas, eventualmente são discutidas nas reuniões da comunidade e, quando há oportunidade, são realizadas com a presença dos funcionários do INCRA. Se no passado as caças eram consideradas uma coisa divina, isto é, um bem que pertencia a todos e, por isso, as pessoas podiam caçar em qualquer área de floresta, no presente as caças são consideradas como uma "coisa humana", isto é, pertence ao proprietário do lote no qual ela se encontra. Diante disso, apenas um entrevistado mostrou-se indiferente, pois segundo ele:

“A caça que está no mato não fui eu quem criou, não gastei nenhum centavo para comprar e criar. Essa caça que tem no mato foi Deus quem deixou e nos deu, então se o amigo tem necessidade porque está com fome, se ele matou uma caça dentro do meu terreno eu não fico brabo por isso, pois era dele, Deus deu para 
ele. Caso encontre algum fulano dentro da minha área caçando eu não vou brigar com ele, não! Sou o mesmo amigo que sempre fui. Ele não está levando o que é meu, ele está levando o que Deus deixou e deu para ele, que não é meu (M.D.P., 59 anos, lavrador e extrativista).

Embora as caças sejam recursos de natureza comum (FEENY et al., 2001), as florestas pertencem aos proprietários dos lotes e, portanto, segundo os entrevistados, eles têm o direito de privar o acesso a elas. Em decorrência disso, as caças que estão em sua propriedade são bens que lhes pertencem. Neste caso, ao entrar e retirar determinada caça sem que tenha o consentimento do proprietário, o "invasor" estará lhe roubando.

A partir dos diversos relatos, constatou-se que o comportamento das pessoas com relação ao acesso às áreas de floresta, em especial para a obtenção de caças, é muito diferente do comportamento que elas tinham no passado. O que ocorreu, tanto em decorrência da mudança de regime de propriedade, agora privado, quanto e, principalmente, por causa da menor disponibilidade de caças, fato proveniente do crescimento populacional ocasionado a partir do assentamento, que além de promover a maior demanda por esse recurso, elevou as taxas de desmatamento (no assentamento de modo geral), fragilizando as condições de sobrevivência das caças.

Os argumentos de Hardin (1968) a respeito da relação que há entre superpopulação, maior pressão de uso e exaustão dos recursos comuns, correspondem à situação que ocorre com o uso das caças na comunidade estudada, na qual a demanda excede em muito a sua oferta. No entanto, os problemas a respeito disso ocorreram a partir do estabelecimento da propriedade privada, o que contrapõe os pressupostos desse autor acerca de que ela seria a solução para a "tragédia dos comuns".

Segundo Mccay e Acheson (1987), há vários estudos empíricos que não confirmam a tese de que proprietários privados tenham maior responsabilidade ecológica e social em relação a populações que manejam recursos naturais de forma coletiva. Além do quê, há vários estudos de populações humanas que asseguram a gestão dos recursos naturais através de regras e acordos definido por elas próprias (SCHMITZ; MOTA; SILVA JUNIOR, 2006; CUNHA, 2002). No entanto, é relevante considerar que a intervenção de agentes externos, entre outros fatores, pode contribuir para fragilizar ou inviabilizar a gestão de determinado recurso (OSTROM, 1990).

\section{REFLEXOES FINAIS}

No passado, os dois usos da floresta de maior importância para a dieta alimentar das famílias nativas da comunidade Santa Maria, espacializada no assentamento Olho D’Água II, localizado no município de Moju, nordeste paraense, foram a caça e a roça, num contexto em que a disponibilidade de floresta era abundante e a pressão humana por seu uso era pequena. Nesse período, os tipos de regime de propriedade existentes que possibilitaram o acesso a áreas de floresta para esses usos foram: áreas próprias (com ou sem a regularização da posse), áreas devolutas (ausência de direitos de propriedade bem definidos), áreas arrendadas e áreas concedidas (comodato). Para isso, foram estabelecidos alguns acordos, aceitos e respeitados pelas famílias que ali residiam, os quais dificilmente eram transgredidos e raramente ocorriam conflitos entre essas famílias.

Diferentemente de algumas populações ribeirinhas e extrativistas que habitam as florestas da região amazônica, para a população estudada, o consumo das caças teve muito mais importância do que o da pesca, devido à elevada disponibilidade dos animais, a preferência alimentar das pessoas que ali residiam e pelo fato de ser muito mais estratégico obtê-los, visto que lhes forneciam uma farta quantidade de carne, o que lhes favorecia um tempo maior para se dedicarem a outras atividades, em especial aos trabalhos das roças.

No passado, estratégias individuais (caçadas) e coletivas (mutirão para roça) eram exercitadas a partir de relações de parentesco e/ou vizinhança, diferente do presente, em que as familias recorrem ocasionalmente às estratégias de práticas coletivas (roça) e as individuais (caçadas) são acionadas com bem menos frequência. No presente, a roça é o uso da floresta de maior importância para a produção de culturas alimentares para as famílias daquela comunidade, num contexto em que há uma forte pressão humana por esse recurso. Devido a isso, as condições de sobrevivência e reprodução das caças são cada vez mais difíceis e, como consequência, o uso da carne desses animais por essas famílias tem sido menor, substituindo-a por outros alimentos, principalmente o charque e a carne bovina, adquiridos pela venda da farinha de mandioca.

Com o estabelecimento da propriedade privada, via assentamento, o acesso das famílias às áreas de florestas para a obtenção das caças é, em geral, apenas na área de seus lotes. Esta nova situação, aliada à pouca oferta desse recurso, torna cada vez mais difícil a sua obtenção, sendo necessário investir um maior 
tempo nesta atividade, e nem sempre se consegue obter algum animal, fato que desmotiva as famílias a se dedicarem a isso. Elas têm buscado novas estratégias de sobrevivência, sendo a principal a especialização na realização de roças, em especial o cultivo da mandioca.

Para a realização das roças, há três tipos de acesso às áreas de floresta: privado, comum e comodato, sendo que o primeiro é o mais representativo, e o último, destinado apenas a parentes e somente em situações de extrema necessidade, pois as famílias têm maior preocupação com a disponibilidade de floresta necessária ao emprego da técnica de corte e queima. Há também uma preocupação com as áreas que destinarão aos filhos quando estes se casarem, tendo em vista que não há lotes destinados a eles e a possibilidade de adquirirem terras nas comunidades próximas é cada vez menor. Essas razões fazem do comodato um tipo de acesso raro, semelhantemente ao caso do acesso comum, porém, com uma diferença, por este acesso desqualificar as pessoas do papel de proprietárias da terra.

Raramente ocorrem conflitos relacionados às roças, no entanto, as famílias têm de se desfazer de suas criações de suínos por causa de constantes invasões destes nas roças de lotes confinantes. Assim, as famílias perdem uma de suas importantes fontes de alimentação, principalmente no contexto em que há menor disponibilidade da carne de caças. Com relação a estas, estabeleceram-se novas regras de uso, que geralmente são transgredidas e, por causa disso, tem ocorrido vários conflitos entre as famílias.

Diante das mudanças que ocorreram nas regras e no uso da floresta, considera-se que houve uma importante influência dos funcionários do INCRA, seja através de "recomendações" ou de imposições para que as caçadas sejam evitadas, quer seja por não serem consideradas como trabalho, quer seja por desviarem a atenção da agricultura, que muitas vezes é considerada a essência da atividade rural.

No contexto em que há uma enorme dependência da floresta para a realização de roças, e diante da menor disponibilidade desse recurso, o período de pousio tem sido cada vez menor, mesmo sabendo-se de sua importância para recuperar a capacidade reprodutiva do solo cultivado. Apesar deste fato ainda não comprometer a viabilidade da técnica de corte e queima empreendida para a realização de roças, tem tornado a sobrevivência e reprodução social das famílias cada vez mais vulneráveis.
Tanto no passado quanto no presente, o uso das caças destinou-se fundamentalmente para o autoconsumo da família, direcionada em especial aos mamíferos terrestres de médio e grande porte. Estas são as espécies mais valorizadas por sua carne, principalmente por causa de seu porte, que implica em um maior retorno de proteína animal por unidade de esforço de caçada.

\section{REFERÊNCIAS}

ALMEIDA, M. B. de; LIMA, E. C. de; AQUINO, T. V. de.; IGLESIAS, M. P. Caçar. In: CUNHA, M. C. de.; ALMEIDA, M. B. de (Orgs.). Enciclopédia da floresta - o Alto Juruá: práticas e conhecimentos das populações. São Paulo: Companhia das Letras, 2002.

ADAMS, C. As populações caiçaras e o mito do bom selvagem: a necessidade de uma nova abordagem interdisciplinar. Rev. Antropologia, São Paulo, v. 43, n. 1, p. $145-182,2000$.

ALLEGRETTI, M. H. Políticas para o uso dos recursos naturais renováveis. In: SACHS, I.; CLÜSENER-GODT, M. (Orgs.). Extrativismo na Amazônia Brasileira: Perspectivas sobre o desenvolvimento regional. Montevidéu: UNESCO, 1996.

BARRETO FILHO, H.T. Populações tradicionais: introdução à crítica da ecologia política de uma noção. In: ADAMS, C.; MURRIETA, R. Sociedades Caboclas Amazônicas: modernidade e invisibilidade. São Paulo: Senac, 2006. p. 109-143.

BENJAMIN. Agroextrativismo: sustentabilidade e estratégias na Reserva Extrativista do Rio Cajari, Sul do Amapá. 2003. 135 f. Dissertação (Mestrado em Agriculturas Familiares e Desenvolvimento Sustentável) - Núcleo de Ciências Agrárias e Desenvolvimento Rural, Universidade Federal do Pará e Empresa Brasileira de Pesquisa Agropecuária - Amazônia Oriental, Belém, 2003.

CARMO, M. S. do. Desenvolvimento Territorializado: Assentamentos Rurais e Agroecologia. In: FERRANTE, V. L. S. B.; ALY JUNIOR, O. (Orgs.). Assentamentos Rurais: Impasses e Dilemas (uma trajetória de 20 anos). São Paulo: Instituto Nacional de Colonização e Reforma Agrária, 2005.

CUNHA, L. H. Manejo comunitário de recursos naturais na Amazônia: arranjos institucionais e mediação externa. 2002. 196f. Tese (Doutorado em Desenvolvimento Sustentável do Trópico Úmido) - Núcleo de Altos Estudos Amazônicos, Universidade Federal do Pará, Belém, 2002. 
DIEGUES, A. C. O mito moderno da natureza intocada. São Paulo: Hucitec, 1996.

FEENY, D.; BERKES, F.; McCAY, B. J.; ACHESON, J. M. A tragédia dos comuns: vinte e dois anos depois. In: DIEGUES, A.C.; MOREIRA, A. de C.C. (Orgs.). Espaços e recursos naturais de uso comum. São Paulo: NUPAUB/USP, 2001.

FELIPIM, A.P.; RESENDE, R. U.; RIBEIRO, R. Agricultura de pousio e controle ambiental. In. DIEGUES, A. C.; VIANA, V. M. (Orgs.). Comunidades tradicionais e manejo dos recursos naturais da Mata Atlântica. São Paulo: NUPAUB/LASTROP/USP, 2000.

HARDIN, G. The tragedy of the commons. Science, v. 162, p. 1243-1248, 1968.

HOMMA, A.K.O. et al. Redução dos desmatamentos na Amazônia: política agrícola ou ambiental. In: Amazônia: Meio Ambiente e Desenvolvimento Agrícola. Brasília: Embrapa-SPI, 1998.

HURTIENE, T. P. Agricultura familiar e desenvolvimento rural sustentável na Amazônia. Novos cadernos NAEA, Belém, v. 8, n. 1, p. 19-71, 2005.

LACERDA, A. G.; MALAGODI, E. Formas de cooperação e Reforma Agrária. Raízes, Campina Grande, v. 26, n. 1 e 2, p. 93-100, 2007.

LEAL, E. C. Potencial de regeneração da capoeira após preparo de área com queima e sem queima na região Bragantina. 2002. 121f. Dissertação (Mestrado em Agriculturas Familiares e Desenvolvimento Sustentável) - Núcleo de Ciências Agrárias e Desenvolvimento Rural, Universidade Federal do Pará e Empresa Brasileira de Pesquisa Agropecuária - Amazônia Oriental, Belém, 2002.

LEITE, S et al. (Orgs.). Impactos dos Assentamentos: um estudo sobre o meio rural brasileiro. São Paulo: UNESP, 2004.

LOUREIRO, V. R.; PINTO, J. N. A. A questão fundiária na Amazônia. Estudos Avançados, v. 19, n 54, p. 77-98, 2005.

MARTINS, J. de S. O sujeito Oculto: ordem e transgressão na Reforma Agrária. Porto Alegre: UFRGS, 2003.

MCCAY, B.; ACHESON, J. M. The question of the commons: the culture and ecology of communal resources. Tucson: The University of Arizona Press, 1987.
MCKEAN, M.A.; OSTROM, E. Regimes de propriedade comum em florestas: somente uma relíquia do passado? In: DIEGUES, A. C.; MOREIRA, A. de C. C. (Orgs.). Espaços e recursos naturais de uso comum. São Paulo: NUPAUB/ USP, 2001.

MEDEIROS, L. S. de; LEITE, S. (Orgs.). A formação dos assentamentos rurais no Brasil. Processos sociais e políticas públicas. Porto Alegre: UFRS, 1999.

MOTA, D. M. da; MEYER, G.; SATO, R. B.; VIEIRA, P. R. Ocupação e desmatamento no Alto Moju versus conservação e mudanças no uso de seus recursos naturais. In: CONGRESSO BRASILEIRO DE SISTEMAS DE PRODUÇÃO, 7. 2007, Fortaleza. Anais... Fortaleza, 2007. p. 9-25.

NEVES, D. P. A Reforma Agrária Esforçada. In: FERRANTE, V. L. S. B.; ALY JUNIOR, O, (Orgs.). Assentamentos Rurais: Impasses e Dilemas (uma trajetória de 20 anos). São Paulo: INCRA, 2005.

- Assentamento rural: confluência de formas de inserção social. Estudos Sociedade e Agricultura, Rio de Janeiro, n. 13, p. 5-28, 1999.

OLIVEIRA, C. D. de S. Percepção de agricultores familiares na adaptação do sistema de cultivo de corte e trituração. 2002. 140f. Dissertação (Mestrado em Agriculturas Familiares e Desenvolvimento Sustentável) - Núcleo de Ciências Agrárias e Desenvolvimento Rural, Universidade Federal do Pará e Empresa Brasileira de Pesquisa Agropecuária - Amazônia Oriental, Belém, 2002.

OLIVEIRA, A. C. M. de; CARVALHO JÚNIOR, O. de.; CHAVES, R. Gestão Participativa e a Atividade de caça na Reserva Extrativista do Tapajós Arapiuns, Santarém, PA. Revista de Ciências Sociais e econômicas, Campina Grande, v. 23, n. 1-2, p. 42-51, 2004.

OLIVEIRA, R. R. et al. Roça Caiçara. Um sistema "primitivo" auto-sustentável. Ciência Hoje, v.18, n. 104, p. 44-51, 1994.

OSTROM, E. Governing the commons: the evolution of institutions for collective action. New York: Cambridge University Press, 1990.

SCHMITZ, H.; MOTA, D. M. da; SILVA JÚNIOR, J. F. da. Gestão coletiva de bens comuns e conflito ambiental: o caso das catadoras de mangaba.In: ENCONTRO DA ASSOCIAÇÃO NACIONAL DE PESQUISA E PÓS-GRADUAÇÃO EM AMBIENTE E SOCIEDADE, 2. 2006, Brasília, Anais... Brasília, 2006. p. 1-15. 
SILVA, A. L. da. Comida de gente: preferências e tabus alimentares entre os ribeirinhos do Médio Rio Negro (Amazonas, Brasil). Revista de Antropologia, São Paulo, v. 50, n. 1, p. 125-179, 2007.

SIMONIAN, L. T. L. Políticas Públicas, Desenvolvimento Sustentável e Recursos Naturais em Áreas de Reserva na Amazônia Brasileira. In: COELHO, M. C. N.; SIMONIAN, L.; FENZL, N. (Orgs.). Estado e Políticas Públicas na Amazônia: gestão de recursos naturais. Belém: Cejup; UFPA/NAEA, 2000.

SOUSA, R. da P. Granja Marathon: a luta pela terra e a organização do trabalho em um assentamento rural no nordeste do Pará. 2002. 121f. Dissertação (Mestrado em Agriculturas Familiares e Desenvolvimento Sustentável) - Núcleo de Ciências Agrárias e Desenvolvimento Rural, Universidade Federal do Pará e Empresa Brasileira de Pesquisa Agropecuária - Amazônia Oriental, Belém, 2002.

WANDERLEY, M. de N. B.; BRUMER, A.; LOURENÇO, F. A. et al. A exploração familiar no brasil. In: LAMARCHE, H. (Org.). A Agricultura Familiar. Campinas: UNICAMP, 1993. 